\title{
Brokerage roles between cliques: a secondary clique analysis
}

\author{
Elisa Bellotti
}

\begin{abstract}
A common goal when analyzing a social network is to try and determine the cohesive subgroup structure of the network. Some techniques result in complex overlapping structures such as cliques or k-plexes whereas others either partition the network or place actors into unique groups, for example factions or components. A standard method implemented in Ucinet uses the overlapping structure to construct a proximity matrix which can be submitted to a clustering routine to find non-overlapping groups. Once the groups have been determined many analysts relate these to observations they have made involving their data. There are few tecFernandez.The method is demonstrated on an original dataset that was collected in 2006 on 100 social services based in a suburb area of Milan, Italy. The dataset is composed of a matrix that contains directed data collected by asking the spokehniques that take the groups as a starting point for additional analysis with the exception of Krackhardt's work on Simmelian ties. In this paper I examine the roles the actors play in the cohesive structure using the brokerage ideas of Gould and sperson of every social service if he/she knows the other services listed (the list of services having been previously compiled using several sources), together with attribute information. The matrix is analyzed using the clique analysis techniques in the Ucinet software package to find nonoverlapping groups. The results are submitted to Ucinet's brokerage routine and visualized using the Netdraw software package. This analysis offers a new insight into the data, as it is possible to identify what actors play important roles (and which kind of role) in bridging the gaps between the cohesive subgroups.
\end{abstract}

Key words: social networks, subgroups, brokerage, clique analysis

\section{Introduction}

Much work has been done to identify cohesive substructures in networks. Scholars have proposed several methods which look at partitions, like factions or components; which search for cohesive structures, like cliques, n-cliques (Luce and Perry 1949), n-clans, k-plex (Seidman and Foster 1978), lambda sets (Borgatti, Everett and Shirey 1990); or which simply assign actors to specific groups, like core or peripheries (Borgatti and Everett 1999), again based on how much these substructures are cohesive or not. But there are few techniques that take these cohesive subgroups as a starting point for further analysis. One recent exception is Krackhardt's work on simmelian ties, which explores the possibility of analysing actors' roles between groups

Correspondence: E. Bellotti, Department of Sociology, University of Manchester, Bridgeford Street, Manchester, M13 9PL. Tel.: +44(0)161 275 2921. E-mail: elisa.bellotti@manchester.ac.uk 
(Krackhardt 2007) using the E-I index (Krackhardt and Stern 1988).This technique reveals who within a network connects different subgroups in terms of being related not only to people who are strongly embedded in cohesive substructures, but also sending ties to other subgroups. This secondary analysis is interesting, but it shows some weakness I will address in this paper.

Here I want to propose a new way to analyse a network structure that combines two well known techniques: clique analysis and brokerage roles. While these methods are certainly not new, the combination of the two is somehow innovative and offers meaningful insights as it shows not only which actors are embedded in cohesive subgroups and who plays important roles of mediation but also describes what kind of roles these are. The method is demonstrated on an original dataset that was collected in 2006 on 100 social services based in a suburb of Milan, Italy.

The paper also addresses a theoretical claim which will need further work to be empirically tested but shows some potential. The idea is to combine two classic and opposite theoretical standpoints from within the social capital debate: collaboration VS competition and public VS private goods. Here I want to see how these two different perspectives can be combined and coexist within the same social structure.

The first section of the paper offers an overview of the theoretical background on Krackhardt's 'simmelian ties' and Gould and Fernandes' 'brokerage roles' in order to see how is it possible to combine the two methods and what are the limits of these techniques. The second section briefly describes the organisation of social services in Italy, explaining how it has changed in recent years and why we need new and more sophisticated research methods if we are to explore its structure. The third section describes the research project and the data collected, which are analysed in the following section using the method proposed. In the last section I discuss the findings, address theoretical issues and suggest furthers areas of exploration which are needed in order to give strength to the proposed technique.

\section{Background theory}

The 'simmelian tie' is a useful concept that has been proposed by Krackhardt in several articles. In the very first paper (Krackhardt 1998) he builds upon Granovetter's idea of strong ties (1973), which focuses on dyads, extending the concept to triads by way of a discussion of Simmel's analysis of differences between dyads and triads. The latter, Krackhardt observes, allow actors to play several roles not permitted in dyadic interactions. According to Simmel (1983), triads are different from dyads because they are characterised by reduced individuality, reduced individual power and moderated conflict. Krackhardt also notes how implementing the number of actors up to more than three does not change the formal features of the structure, thus he focuses on triads as his units of analysis. Thus, Krackhardt concludes that «the key to understanding the quality of a tie between two actors can be reduced to asking whether it is part of a strong triad or not» (Krackhardt 1998: 24).

He then proposes the definition of simmelian ties, which are ties reciprocated and reciprocally connected to at least one third person. As he points out, this concept resembles the one of clique, defined by Luce \& Perry (1949) as a maximum subgraph connecting at least three nodes. Because the Ucinet (Borgatti, Everett and Freeman 2002) routine that is used to extract cliques needs symmetrical data as an input ${ }^{1}$, we can further specify that simmelian ties are ties embedded in cliques that are extracted after symmetrizing the data at the minimum level (therefore selecting only reciprocated ties).

Even more interestingly, Krackhardt statistically demonstrates that «simmelian ties are "sticky" - that is, they will last longer than other forms of merely strong ties», and that «simmelian ties will occur with greater frequency than would be expected by chance, given the overall structure of the relations» (Krackhardt 1998: 25). This means that simmelian ties, even following a stricter definition than asymmetric or sole symmetric ties (the latter are defined as reciprocated ties not embedded in cliques, see Krackhardt 1999: 186), are «backed up by the normative power of the groups, providing stability beyond that experienced by bridges or isolated dyads» (Krackhardt 1998: 35).

\footnotetext{
${ }^{1}$ This is because ties have to be symmetric in order to fit into the clique definition of a maximum subgraph.
} 
In a subsequent paper Krackhardt (1999) goes further, comparing simmelian ties analysis with Burt's (1992) conception of structural holes effects. While Granovetter has stressed the importance of the quality of the tie (strong or weak) in order to provide advantage to the individual, Burt's analysis only concerns if a tie is a bridge or not, arguing that bridging ties, independently of strength, are less constraining on the actor than non bridging ties. Krackhardt disagrees with Burt's interpretation, because he sees people who act as bridges between cohesive subgroups as constrained by as many sets of rules as the number of groups they belong to. With the concept of simmelian ties the author demonstrates that people embedded in triads are committed to the triadic forces described by Simmel (reduced individuality, reduced individual power, moderated conflict) thus the more subgroups they are embedded into the more constrained they are by these forces. Krackhardt (1999) goes further arguing that his analysis works better when people play public roles, while Burt's analysis is more suitable for private roles. Here the claim goes to a theoretical level, as the author is trying to make a statement about the outcome of individual structural roles in terms of social capital.

Krackhardt analyses the constraint effect of cliques' within an organization in the Silicon Valley $(1992 ; 1999)$ where employers started a union certification drive. He found that people occupying a position of mediation were constrained regarding the expression of their personal point of view due to the fact they belonged to different subgroups; thus the information flow was reduced through structural holes rather than being more effective, as Burt says in his theory of brokerage roles. But Burt's analysis is informed by a concept of social capital as a private and scarce good, which is hard to get and stimulates competition between actors. The Krackhardt's scenario is far more complex than that, as in Silicon Valley there were actors collaborating for the same goal (the union certificate) and competing for different standings (to approve it or not). If we see social capital as a private good that is produced by personal relationship via strategic interactions then it is easier to describe relationships in terms of competitiveness. But such a situation is not always true, as there are many situations in which actors are embedded in social structures that need both competitiveness and collaboration, whose outcome in terms of social capital is both private and collective. I will go back to this point in the next section, where I describe the contemporary scenario which Italian social services are dealing with.

Recently, in his keynote address at the UK Social Network Conference (2007) ${ }^{2}$ Krackhardt has proposed to use the E-I index - defined as the number of ties external to the groups minus the number of ties that are internal to the group divided by the total number of ties (Krackhardt and Stern 1988) - on simmelian ties. This method allows us to explore which actors play important roles of mediation between groups. As such it is both interesting and useful. But it does not allow us to describe what kind of role, and furthermore does not take into account structural holes. It could therefore also be distorted by redundancy in ties.

Here I want to improve upon and develop Krackhardt's insights by using Gould and Fernandez measures of brokerage roles (1989) applied to non overlapping cliques: clique analysis and brokerage roles can be seen in similar terms, as cliques can be defined as transitive triples (because they are formed by reciprocal ties), while «any brokered exchange can be thought of as a relation involving three actors, two of whom are the actual parties to the transaction and one of whom is the intermediary or broker» (Gould and Fernandez 1989: 91) and moreover «brokerage represent an intransitive triple» (Ibid: 97). The authors propose a classification of the forms of brokerage relations that is «an exhaustive listing of the possible types of two-step paths on which any actor may lie, and it is thus an exclusive and exhaustive partition of any actor $\mathrm{j}^{\prime}$ s total raw brokerage score $\mathrm{t}_{\mathrm{j} \text { 》 }}$ (Ibid: 101). They identify five types of roles, according to the direction of the ties and the groups actors belong to. In a situation where $a$ sends a tie to $b$ who sends a tie to $c$ and there are no ties between $a$ and $c$, the five possible brokerage roles of $b$ are:

- Coordinator: $a, b$ and $c$ belong to the same group.

- Itinerant broker (consultant): $a$ and $c$ belong to the same group, while $b$ belongs to a different one.

- Gatekeeper: $a$ and $b$ belong to the same group, while $c$ belongs to a different one.

- Representative: $b$ and $c$ belong to the same group, while $a$ belongs to a different one.

- Liason: all the actors belong to different groups.

\footnotetext{
${ }^{2}$ UK Social Network Conference, 13-14 July 2007, Queen Mary College University of London
} 
The standard method implemented in Ucinet (Borgatti, Everett and Freeman 2002) calculates how many times every actor in a network plays these brokerage roles between groups, giving the total amount of brokerage roles as well. Thus it is possible, once the groups are determined, to explore not only if an actor plays a brokerage role, but also what kind of role s/he is playing and within which groups: given the fact that groups here are cohesive subgroups formed by simmelian ties, this method allows to analyse a network looking only to relational data, without using nodes' attributes (which are normally used to define groups when looking for brokerage roles) unless for a secondary interpretation of the findings.

The importance of proposing a technique that focuses on ties rather than on nodes does not lie only on a methodological level. It has theoretical significance. The social capital debate has been dealing with this aspect since its very first formulation by Bourdieu (1992) and Coleman (1998), the first claiming that social capital is a private resource that people strategically accumulate from the network of relationships they are embedded into, the second assuming that social capital is an unintentional public outcome of human collaboration. Bourdieu's view concerns actors, while Coleman tries to shift the attention to ties. But it has been Putnam, with the distinction between bonding and bridging ties (Putnam 2000), who has definitely tried to move the analysis from actors to ties.

But Putnam's theory has not defined what is actually exchanged through these social capital ties, as the distinction between bonding and bridging rests on the ideas of homophily and heterophily. Bonding ties occur between people in similar situations, while bridging ties connect people in different positions. While the description of the output of these ties does refer to the content of exchange (as bonding ties are useful for the development of reciprocity and solidarity, while bridging ties are valuable resources of innovation), the way in which the author looks at them is based again on actors' attributes, either a quality or a position of the actor. Also Lin's idea of homophily and heterophily (2001) is affected by the limit of considering actors and their position rather than the real exchange that flows through ties. As Barbieri (2005) pointed out, while Lin's theory seems to consider social capital in terms of material and non material resources exchanged within a network, when Lin measures individual social capital with the position generator method he takes into account the positions an actor can occupy mobilising his or her contacts, thus using a status rank.

The method I propose here is built only on relations, as it looks at transitivity within triples (cliques), and intransitivity between non overlapping cliques. The outcome gives a definition of the position an actor occupies within a network and his or her consequent role, but this definition entirely depends on the ties this actor is embedded into.

\section{The scenario: third sector and social capital in Italy}

The research I present here was led by the Centre for the Study of Fashion and Cultural Production of Catholic University of Milan for the social cooperative A77 that addresses substance abuse amongst young people. The cooperative requested a map of the network of social services in a suburb of Milan where it operates: the purpose of the map being to give the cooperative a valid instrument for directing people with a dependency problem to the right service, assuming that dependency is never a problem related to a single aspect of people lives, but needs a multidimensional approach in order to avoid fragmentation of care. Especially when dealing with youth, it is important to involve the complete network of people (adults and peers) the person is in contact with. Carers need to activate a network of intervention, which takes into account the individual in all his or her needs, from school, to work, free time, health services and so on. This also requires the carer to have the adequate resources for suggesting the right service (or several services) that can help the individual in facing different aspects of his or her problem. Relying on other services does not mean passing the responsibility of an intervention to another service but rather activating nurturing collaborations between the public, private and non profit services within a local territory.

Thus, the problem for the cooperative can be reduced to a lack of coordination between the different social services of a suburb, a problem that is related to the shift from the welfare state to what has been called the third sector. Folgheraiter (2006) describes this shift as a change from the right to be assisted, typical in a welfare state, to the duty of feeling good, where the social system has to offer standardised and rationale services sustainable from an economic point of view. The rationalisation of the system needs specialised 
services that can be sold on the market of the new welfare, in which the policy buys social work according to an optimization of budget and resources. This shift from the right to be assisted, that needed a welfare state, to the duty of feeling good, which is based instead on the market optimisation of the social services, has produced an increasing distance between social policy and social work. The first is concentrated into making laws that optimise the system, creating quality standards and dealing with the budget, while the second is fragmented into a multiple micro reality where there is a lack of a general view and of coordination.

The general idea is thus that social work is just the executive aspect of social policy, without a general overview and the capacity of planning at the macro level. Furthermore, consumerism has infected the social system, as services are seen as pre-made and standard goods that can be sold on the market, while according to Folgheraiter (2006), a helping offer, as social capital, can be produced only by social relationships. The social capital perspective here is the one of Coleman (1998), who intends it as an emergent good that is produced by the network of relationships and goes beyond the individual interest becoming a public good whose effects spread on the entire community.

Folgheraiter (2006) describes the contemporary Italian system of welfare as a «quasi-market», as the government (national as well as local) assure free interventions for citizens, granting everyone the right of a social and health system, but it buys these services on a semi market that is organised and controlled by policy makers via outsourcing and commitment. This mixed logic (of public welfare and semi-private market) has lead to an increased competition between the social services, as they have to win funding and prove quality, but the quality standards are based on the process of services (how much does it cost? How long does it take?) more than on products (is it actually effective? Does it improve the life standard of problematic people?). Also the author notes that the main idea behind a welfare system is to offer ready-to-go solutions, in terms of a full package of intervention that weaken the individual and collective ability of problem solving. This means that the welfare system has weakened social capital, meaning that the capacity to activate a network of relationships when facing a problem is reduced.

In such a situation, social network analysis is the right instrument not only to map the various connections between the social services, but also to identify the roles of actors within the network.

\section{The data}

The data I present were collected in autumn 2006 for a research project commissioned by a social service (A77) that deals with any kind of addiction and it is based in a suburb of Milan. The purpose of the project was to map the network of all public and private institutions and firms that offer any kind of activity and support for youths. Because A77 deals with addiction, the main goal of the research was to map all the services can address the complex needs of problematic youth, according to the idea that a good intervention can be effective only when it activates the complete network a person is embedded into.

The research involved two phases:

1. I identified all services that offer youth activities and support in the suburb of Milan where A77 operates. This search was conducted by Internet as well as through examination of archives for any kind of service that corresponded to research criteria (i.e. served young people aged between 15 and 30 years old).

2. I sent a questionnaire to every service mapped in the first phase (the initial number was 127, but I cut it down sampling some of the categories, like churches and gyms), asking for details on the kind of service (public, private, non profit), the average number of people served, the kind of activities offered. This information has been coded as attributes, according to:

a. The kind of service $\left(\right.$ kindser $\left.^{3}\right)$ : these are coded as following:

\section{1. churches}

\footnotetext{
${ }^{3}$ We code the kind of attribute with a tag that reminds the nature of the attribute. These are the tags we will use during analysis in referring to a specific kind of attribute.
} 
2. psychological services

3. sporting clubs

4. cultural and artistic centres

5. social coop

6. instruction and education institutes

7. youth clubs

8. international cooperation (one case)

\section{b. The institutional typology (type):}

1. profit

2. non profit

3. public

4. religious

c. The age of people served (age, see Table 1). Even if I selected services according to the young age of people addressed, some services do address also adults as well as elderly people:

\section{Table 1: age of people served}

$\begin{array}{llll}\text { Code } & \text { Category } & \text { From } & \text { To } \\ 1 & \text { All ages } & 0 & 99 \\ 2 & \text { From late infancy } & 10 & 99 \\ 3 & \text { Adults } & 25 & 50 \\ 4 & \text { Children - Teenagers } & 5 & 25 \\ 5 & \text { Children - Youth } & 6 & 40 \\ 6 & \text { Elderly } & 50 & 99\end{array}$

\section{d. The kind of problems the services address (problem):}

1. Children with familiar problems

2. Marginalised people (homeless, illegal immigrants)

3. Drug and alcohol addicted

4. Foreigners

5. Disabilities

6. Non problematic people

e. The activities offered (activ): these are listed in a affiliation matrix, where rows are social services and columns are activities, like courses in painting, writing, reading, DIY, dance, yoga, foreign languages, Italian language, theatre, music, cinema, computer, as well as psychological counselling, legal counselling, school support, job an school orientation, family support, religious meetings, peer aggregation.

Next I listed all the services and asked participants to indicate which they knew. I also asked if they knew other similar services. This latter question generated 50 new names that I added to the original list and resubmitted to all participants. In some cases it was not possible to obtain data, as services refused to answer the questionnaire (one case) or, as public services, they needed special authorization from the city council that would take too long. I thus collected data on 100 social services, for which I construct an adjacency (actor by 
actor) matrix containing data on the knowledge each service has of all the others; I call this matrix the knowledge network. An analysis of the knowledge network is an important preliminary step to an analysis of collaborative and other stronger ties. It is firstly important to see if individual service providers are aware one of the other, as they would never be able to activate collaborations if they do not know that other services exist in the area.

Then I asked these services if they ever collaborate together: again, the data on the 100 social services were stored in a matrix that I called the collaboration network. This network is more interesting in terms of social capital, as it reveals the size of existing collaborations, thus ties here are more meaningful than the simple knowledge network. The problem is that it is not possible to apply the method I want to propose on this network, because as I previously said, brokerage roles can be measured only for directed data, for they entail, by definition, intransitive triples. The collaboration network I mapped is indeed directed, but the lack of symmetry in ties is due to the fact that some services (especially bigger or older ones) might not remember all the collaborations they activated in the past, while smaller or newer services will probably recall more outgoing ties. But collaboration is by definition a symmetric tie, as it is not possible to collaborate with someone who does not collaborate back. Due to the fact brokerage roles cannot be measured for this network, I decided to apply the method only on the knowledge matrix.

This generates another limitation in the analysis, as we should assume that in order to be brokers people must be aware of their role. By definition, a broker is someone who plays an intermediary role between two others, and the term originally refers to a business context, even if it can be used more widely, including the senses of jobber, agent, factor, or commission-agent. Here I stretch the sense of the term referring to anyone who is in the middle of a structural hole (Burt 1992) no matter what is the context. What I am looking for here is then the potential role some services can play in order to increase the collective awareness of the local offer, as well as their strategic position within the network in terms of competition against same kind of services. The brokerage roles here are then intended as potential key roles in terms of diffusion or control of the circulation of information.

\section{Method and findings}

Before analysing the network in order to find brokerage roles between cohesive subgroups it is useful to run some preliminary analysis that describes the overall structure of the network. The knowledge network activates only the $15 \%$ of possible ties but 93 out of 100 nodes belong to the strong component, and the average distance is 2.3 nodes. Thus, even with a low density, the knowledge network is somehow well connected, as most of its nodes are reachable by others with an average short path.

As the goal of the analysis is to reveal the structure for potential synergies, I then analyse densities between different groups, where these groups are defined by nodes' attributes. First of all I calculate the average value of density between different kinds of services (kindser), see Table 2: 
Table 2: Density / average value within blocks (kindser)

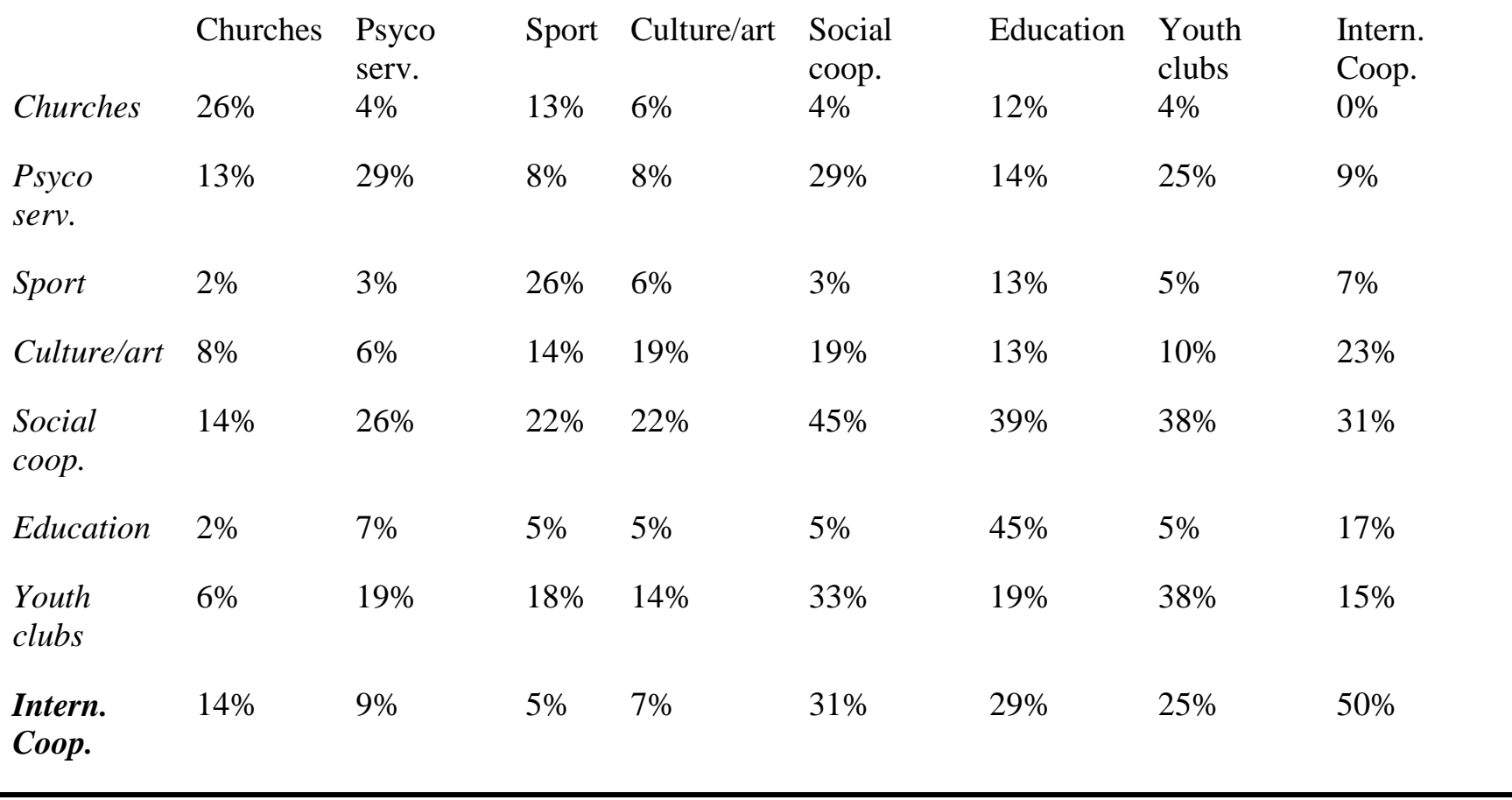

The density matrix, partitioned by the kind of service, shows that psychological services seem to know better social cooperatives (activating the $29 \%$ of the possible ties) and youth clubs (25\% of possible ties); on the other hand, social cooperatives know better psychological services (26\%), sporting clubs and cultural and artistic centres (22\%), instruction and education institutes (39\%) and youth clubs (38\%). Finally, youth clubs know better social cooperatives (33\%). Indeed diagonal values (indicating awareness of same kind of services) are not dramatically high, but they are still higher than other values, especially regarding social cooperatives (45\%), instruction and educational centres (45\%) and youth clubs (38\%). Values for group 8 are not significant as there is only one service belonging to this group.

Average values of density partitioned by the institutional typology of centres (type) are shown in table 3 :

Table 3: Density / average value within blocks (type)

\begin{tabular}{lllll} 
& Profit & Non profit & Public & Religious \\
Profit & $24 \%$ & $6 \%$ & $11 \%$ & $7 \%$ \\
Non profit & $13 \%$ & $18 \%$ & $10 \%$ & $13 \%$ \\
Public & $22 \%$ & $11 \%$ & $23 \%$ & $17 \%$ \\
Religious & $9 \%$ & $11 \%$ & $3 \%$ & $23 \%$ \\
\hline
\end{tabular}


Here values (also diagonal ones) are even lower than before, meaning that the public sector, as well as the private, the non profit and the religious one again enjoy only a poor knowledge of the existence of other services, even within the same category as them.

Finally Table 4 shows average values of density partitioned by the age of people served (age):

Table 4: Density / average value within blocks (age)

\begin{tabular}{lllllll} 
& All & Late inf. & Adults & Child/teen & Child/youth & Elderly \\
All & $15 \%$ & $14 \%$ & $10 \%$ & $17 \%$ & $16 \%$ & $3 \%$ \\
Late inf. & $12 \%$ & $13 \%$ & $13 \%$ & $19 \%$ & $10 \%$ & $0 \%$ \\
Adults & $13 \%$ & $8 \%$ & $8 \%$ & $12 \%$ & $8 \%$ & $25 \%$ \\
Child/teen & $12 \%$ & $16 \%$ & $19 \%$ & $29 \%$ & $12 \%$ & $0 \%$ \\
Child/youth & $13 \%$ & $9 \%$ & $6 \%$ & $12 \%$ & $13 \%$ & $0 \%$ \\
Elderly & $16 \%$ & $9 \%$ & $25 \%$ & $6 \%$ & $11 \%$ & \\
\hline
\end{tabular}

Here we can notice that only services addressed to adults and elderly are aware of each other, meaning there is not intergenerational contact. Services for children and teenagers show the highest value on diagonal, meaning that they are aware of the local offer for people of this age.

Looking at densities partitioned by attributes, while interesting, does not allow us to explore the specific role of every actor within the network. Moreover, it is based not on the structure of the network, but on actors' attributes. The method I propose here allows us to overcome these two main problems, as it refers only to relational data and gives details of each actor's roles. The method implies several steps: the first step is to identify and select symmetrical (reciprocated) ties only, discarding non-reciprocated ties for the purposes of this analysis. This step is mandatory because cliques are by definition maximally complete subgraphs, and if there are directed and non symmetric ties the subgraph would not be maximal. Because the ties are symmetrised and embedded in cliques, they can be considered as simmelian ties, or transitive triples. The subsequent step consists into submitting the matrix to Ucinet routine that analyses cliques. This routine allows setting the minimum size of the clique: a good way to run clique analysis is then to find the best size of cliques in order to reveal a structure where the number of cliques is not too high and it does include as much nodes as it can. Thus I set the minimum size of cliques at 4 , and I found 18 cliques which involve 33 out of 100 nodes.

Ucinet then automatically submits the clique output to hierarchical clustering to find non overlapping cliques, which means intransitive triples. Figure 1 shows the hierarchical clustering of overlap matrix. We can now visualise the actor by actor co-membeship matrix via Netdraw (Borgatti 2002) where the size of the ties represent the number of cliques two nodes share in common (see Figure 2). If we do not consider isolates, we see that the network has two main components showing a very interesting structure. There are nodes connecting different parts of the network, acting as bridges between denser parts. An isolate position here does not indicate that these services do not activate any ties, but only that they do not activate simmelian ties. Thus it is arguable that there would be services within cliques' groups and outside them (isolates) that can act as bridges in the network. 


\section{Figure 1: Hierarchical Clustering of overlap matrix}

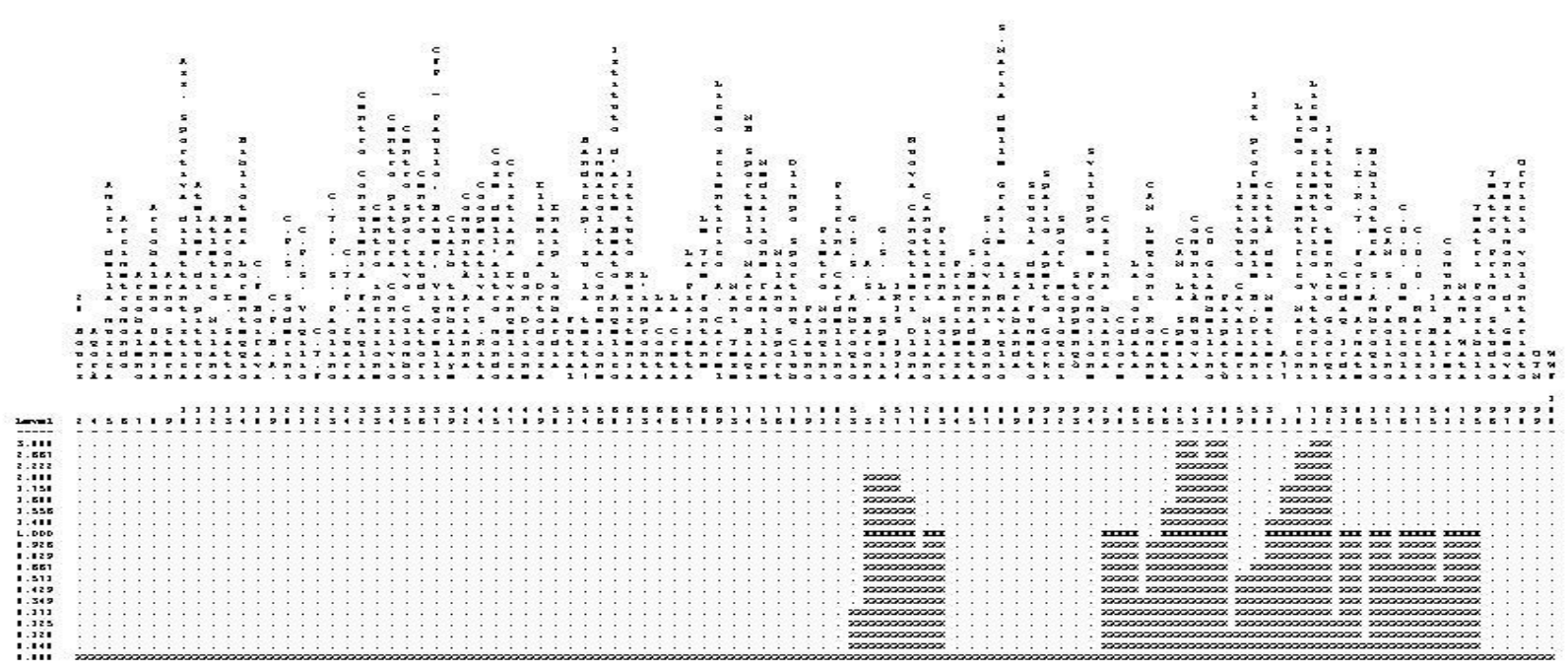

Figure 2: Visualization of cliques co-membership matrix.
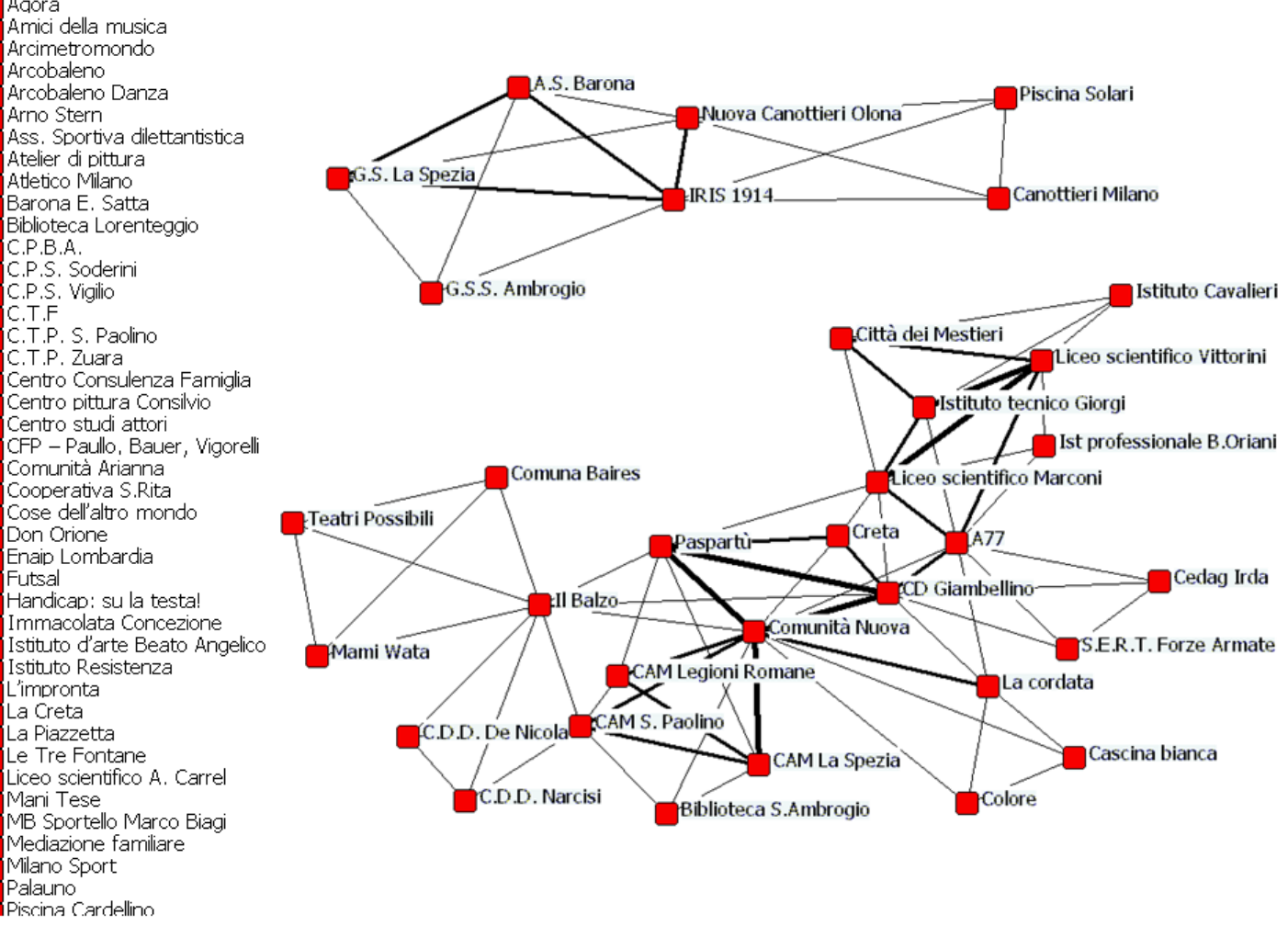

Size of ties $=$ no. of cliques in common 
In order to reveal these bridging roles, I decided to start from the clique structure and identify these positions using the measure for brokerage roles. Gould and Fernandez' technique for identifying brokerage roles is based on the idea that brokers connect people according to the groups they belong to: thus I decided to divide the network into groups according to the non overlapping clique structure. Using the hierarchical cluster analysis of overlapping cliques (each comprising 4 nodes) I select the level on which we can identify the maximum number of towers (that is level 1 , which means that people clustered in the same tower share an average of 1 clique together, see Figure 1) and assign a number to people belonging to the same tower.

At level 1 we find 9 groups:

1. Sporting clubs

2. Sporting clubs

3. Supporting services for problematic youth dedicated to solidarity actions

4. Youth clubs (youth clubs and leisure services)

5. Schools and education services

6. The public drug addiction centre and a youth club

7. A youth club and a public library

8. Disabilities centres

9. Arts associations

Isolates are joined in group 0, as they do not belong to any clique overlap structure. Figure 3 shows the previous actor by actor co-membership matrix, where nodes have been shaped according to the 9 nonoverlapping groups (plus group 0) and the size of ties represents the number of cliques two nodes have in common. If we now visualize the original knowledge network and colour the services according to the clique groups they belong to (Figure 4), we have an overview of the whole network and the clique structure embedded in it. We can thus search for services that activate simmelian ties (meaning they are well connected within their own group) but at the same time are in a good position to mediate or control the circulation of information between other groups and, more importantly, between services that do not belong to any cohesive substructure. 
Figure 3: Visualization of cliques co-membership matrix with group belonging
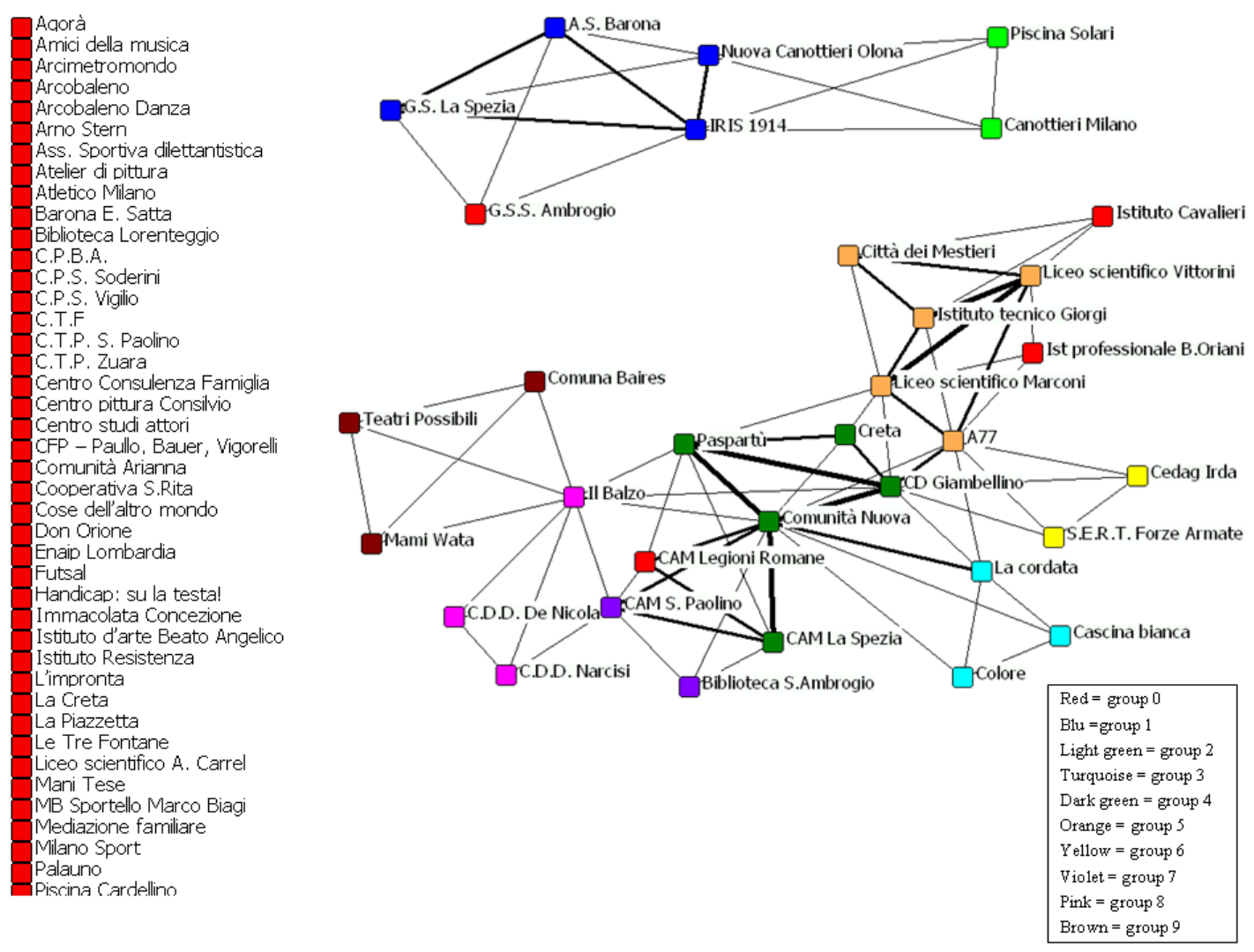

Size of ties $=$ no. of cliques in common

Figure 3: visualization of the whole knowledge network coloured by clique groups

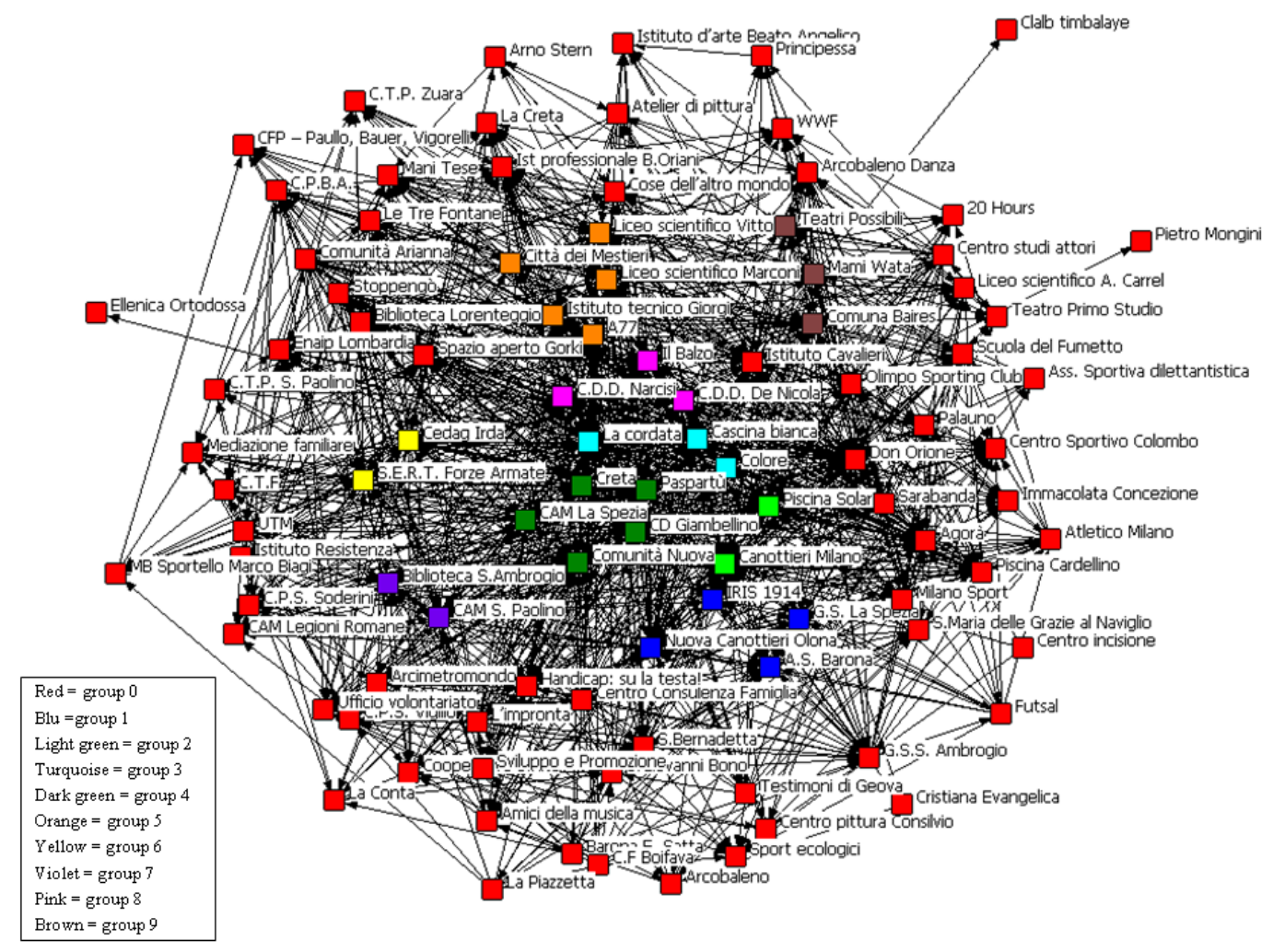


As the density and clique analyses have shown, services tend to know other services if they are similar or they offer similar activities. For our purposes, this situation is not useful when dealing with problematic youth, as they should be able to activate links with services that offer different activities and different support. Moreover, cliques involve only 33 out of a 100 nodes, meaning that the 67 isolates do not belong to any cohesive substructure and do not activate many symmetric ties. This means that social services could surely improve the circulation of information regarding local services, investing in services that can spread such information around the network. These services can be identified through the brokerage role analysis applied on cohesive substructures, in a way in which well connected nodes can act as bridges between different cliques and these cliques and isolates. On the other hand, the analysis of these roles, given the features of every service, can help to clarifying whenever a service could possibly have an interest into increasing the flow of reciprocal knowledge between services (like in the case of the committee, whose aim is to know different service where to address problematic youth) or could actually prefer to keep information for itself, like in the case of market oriented services (like gyms) that can use their knowledge of the local offer as an advantage against competitors.

The Gould and Fernandez's brokerage routine gives two main outputs: the first one summarises brokerage roles' scores of every actor, providing the total number of times they play a specific role as well as the sum of all the roles (see Table 5). The second output provides detailed scores about which groups every actor plays a specific role between. Table 6 reports an example of this second output, calculated for the Sporting Club Nuova Canottieri Olona, which belongs to group 1.

Table 6: Detailed scores of brokerage roles for Nuova Canottieri Olona (group 1)

\begin{tabular}{l|llllllllll}
\hline Group & $\mathbf{0}$ & $\mathbf{1}$ & $\mathbf{2}$ & $\mathbf{3}$ & $\mathbf{4}$ & $\mathbf{5}$ & $\mathbf{6}$ & $\mathbf{7}$ & $\mathbf{8}$ & $\mathbf{9}$ \\
\hline $\mathbf{0}$ & 120 & 47 & 6 & 0 & 0 & 43 & 0 & 0 & 18 & 0 \\
$\mathbf{2}$ & 22 & 0 & 1 & 0 & 0 & 9 & 0 & 0 & 3 & 0 \\
$\mathbf{3}$ & 13 & 4 & 0 & 0 & 0 & 6 & 0 & 0 & 1 & 0 \\
$\mathbf{4}$ & 3 & 4 & 0 & 0 & 0 & 2 & 0 & 0 & 1 & 0 \\
$\mathbf{5}$ & 3 & 5 & 2 & 0 & 0 & 0 & 0 & 0 & 2 & 0 \\
$\mathbf{6}$ & 0 & 2 & 0 & 0 & 0 & 0 & 0 & 0 & 1 & 0 \\
$\mathbf{7}$ & 4 & 0 & 0 & 0 & 0 & 0 & 0 & 0 & 0 & 0 \\
$\mathbf{8}$ & 1 & 1 & 1 & 0 & 0 & 3 & 0 & 0 & 0 & 0 \\
$\mathbf{9}$ & 8 & 2 & 0 & 0 & 0 & 0 & 0 & 0 & 0 & 0 \\
\hline
\end{tabular}

Coordination role: value in cell row2; col2 (group 1 diagonal).

Representative role: values in row2. (Eg: Nuova Canottieri Olona plays 22 times a representative role between its own group 1 and group 0 ).

Gatekeeping role: values in col2 (Eg: Nuova Canottieri Olona plays 47 times a gatekeeping role between its own group 1 and group 0 ).

Consultant role: all diagonal values apart from row2; col2.

Liaison role: values in all other cells apart from the ones of previous roles. 
Every role has its own meaning. Being the coordinator means that the service in a group is known by others and knows others itself: such a role within the isolates group is useful to increase (or not) the reciprocal awareness of the group, as services in this position could let (or stop) information circulating in the network. Representative services instead receive (and send ${ }^{4}$ ) ties within their own group but only send ties outside the group, thus they are good resources to let (or to stop) the actors of the group to be known by others. Gatekeepers only receive ties from outgroups, meaning they can favor (or control) circulation of information within their own group. Consultant services receive and send ties to actors in the same group that is different to the one they are embedded into: they can thus increase or not the cohesion of other groups. Being a liaison involves sending and receiving ties between two different groups that are both different from the one the actor is embedded itself: again, this could mean increase or not of the cohesiveness of the whole network.

\section{Discussion}

I can now analyse the roles of every actor within the network. The first thing we notice is the low values on coordination roles for every group: this is expected, as nodes are well embedded within their groups, which represent overlapping cliques. Some of the low values (for examples in group 4, for Comunità Nuova nd Paspartù) are explained by the fact that cliques have a minimum size of 4 nodes, and groups were selected taking services which shares at least one clique in common. This means that not everyone in the group has to share all the cliques with the other three in its clique, and between different cliques there could be the space for a coordination role.

Within every group is it possible to identify a leader, who has the highest values for most of the roles: for group 0 (people who do not share any clique in common and are visualised as isolates) the leader is Don Orione, a catholic church which offers services for youth, the elderly, and handicapped women. Don Orione has the highest values on coordination within its own group. Due to the fact that the goal of the church is to increase social support within the local community, we can interpret its coordinative role in terms of mediation between the group, as it can spread awareness of the local service to other services that seem to be fairly isolated in the area. The representative role is lead by Institute Cavalieri, a public school that at level 0.571 of hierarchical clustering joins group 5 (school and education services). The Institute is then a good resource of connection between fairly isolated social services and the local educational system. Again, the role of the school can be understood in terms of mediation, as it is not in competition with other schools in the area (that have a different educational offer). Thus we can suppose that the institute could easily pass information to others in its group regarding educational services in the area. The gatekeeping role is covered mostly by Sporting Club S. Ambrogio, which is dedicated to sport courses including gym, volley, judo, basketball. This club joins group 1 (sporting clubs) at level 0.171: here this role can be intended as a source of advantage in the competitive field of local private sporting clubs, because the gatekeeper role allows the club to control information flow between group 0 and group 1 and to strategically limit contacts between other competitors sporting clubs and the isolated services. The sporting club S. Ambrogio covers the same gatekeeping role with group 8 (disabilities centres). This last group will tend to contact the sporting club when it needs to address handicapped youth to sport activities. The same sporting club shows higher values on liaison, confirming its strategic position within the network, while within group 0 there are no significant values for the consultant role. Note that Don Orione, Institute Cavalieri and Sporting Club S. Ambrogio, regardless of the significance of their position in terms of collaboration VS competition, play very important roles in front of group 0 , as they allow and/or control information flows within the group and between other groups; the loosely connected group 0 (which is the most numerous groups, with 67 nodes) needs such brokers to improve its connectivity.

Group 1 (sporting clubs) is entirely dominated by Nuova Canottieri Olona (see Table 6), a multifunctional sporting centre offering courses in swimming, fitness, tennis. The centre shows high values of liaison between group 0 (isolates) and group 5 (educational system), group 0 and group 8 (disabilities centres) and group 2

\footnotetext{
${ }^{4}$ All the services embedded in cliques do have, by definition, symmetric ties within their own group. Thus when they play representative or gatekeeper roles we have to keep in mind that these roles are counted because they mostly receive or mostly send ties outside of their groups, while inside of them they both send and receive ties. This is also the reason why apart from isolates (where services are not embedded in cliques) these structures show very low values in terms of coordination, as in these structure actors are reciprocated and reciprocally connected to a third part (simmelian ties).
} 
(sporting clubs) and group 0 . This means it is in a strategic position from which it can pass information between isolates, the public educational system and the sector dedicated to handicapped youth. Also, as we can see from Figure 3, group 1 shares a variable number of cliques only with group 2, as well composed by sporting clubs. In this case we can suppose that the liaison role between group 2 and group 0 facilitates control of information, as the group 2 sporting clubs are located very close to Nuova Canottieri Olona (especially Canottieri Olona, which is in the same street and has a very similar name, thus the two could also be confused). Here the liaison position allows Nuova Canottieri Olona to gain a strategic advantage over the other sport services.

Group 2 comprises the swimming pool Solari, which has the highest values on consultancy (between group 0) and liaison (especially between group 0 and group 1 and group 0 and group 8) and Canottieri Olona, another sporting club specialised in tennis and rowing which shows high values on gatekeeping with group 0 . This group shares an average of 0.829 cliques with group 1 . Here all the roles can be interpreted as controlling the information flow, especially regarding group 0 . The special relationship between group 8 (disability centres) and all sporting clubs is easily understood as disability centres always offer a sport program to their users, and chose the sporting centre according to availability and closeness.

The group 3 leader is La Cordata, a solidarity social cooperative born in 1989 from a group of practitioners of Agesci (a catholic association of boy scouts) dedicated to marginalised youth. It offers many kinds of activities and structures, from youth and student hostels to family support. It has a consultancy role for group 0 (isolates) and group 5 (educational services), it represents its own group in front of groups 0,1 and 2 (sporting clubs), 4 (youth clubs) and 5. It is a gatekeeper between groups $0,4,5,6$ (drug addiction centre) and 9 (art associations). Therefore it occupies a very strategic position, but due to the non-profit nature of the service we can possibly interpret its role in terms of increasing collaborations rather than competition.

Group 4 (youth clubs) is dominated by Comunità Nuova, a non-profit association dedicated to drug addicted, marginalised youth and immigrants. It has high values on consultancy for group 0 and on liaison between group 0 and other groups, therefore it can potentially increase cohesiveness of the isolates. It is also the coordinator and the representative of its own group in front of all the other groups except groups 2 and 6 . An advantage of the method presented in this paper is that it is possible to verify if there are other services that can act as representative for groups that are not connected to the leader. This is the case with Paspartù, ad educational centre that shows higher values for group 6 and CD Giambellino, a multifunctional youth club that has higher values in front of group 2. Therefore these are the centres group 4 needs to turn to in order to gain information on the public service of drug prevention and sporting clubs.

Group 5 is composed by educational institute and the social cooperative $\mathrm{A} 77^{5}$, dedicated to prevention of addiction. Here brokerage roles are better distributed, as the gatekeeping is covered by A77, representative and consultancy by Institute Giorgi and liaison by the high school Marconi, which also shows higher value on total brokerage score.

In group 6 gatekeeping and consultant roles are taken by Ser.T, the public drug addiction service, while Cedag Irda, a youth club that offers education and family support shows higher values on representative and liaison roles. The high indegree value of Ser.T can be explained by the fact that all the other local services address youth with addiction problem to the public health services, which receives more ties than it sends out.

Within group 7 we find youth club S. Paolino, dedicated to recreational activities and specialised in a representative role between its group and group 0 and liaison roles between group 0 and group 1 (sporting clubs), group 0 and group 8 (disability centres), and group 4 (youth clubs) and group 0 . We also find the public library S. Ambrogio, with higher values on gatekeeping and consultancy for group 0 . As we can see, there are many services that can improve the information flow within group 0 and between this group and the others, thus increasing the connectivity of the whole network.

Group 8 is composed of centres for handicapped people and Il Balzo, a non profit association that offers courses of art and dance especially for handicapped people. The double vocation of Balzo (art and voluntary

\footnotetext{
${ }^{5} \mathrm{~A} 77$ is also the research commitment.
} 
work for handicapped people) is expressed by its brokerage role between its group and group 9 composed of cultural, theatre and art association and dominated by Comuna Baires. This is an Argentinean association that promotes artistic activities like tango dance, painting and theatre.

Focusing the attention on social services that are able to activate ties outside their own cohesive subgroups allow us to discuss two different but correlated aspects of social capital. In the quasi-market of Italian welfare the public, private and non profit services compete against each other for economic funding to invest in projects and increase newcomers. In this perspective a brokerage role can be an advantage in terms of controlling information flows from different local resources. Being a gatekeeper, like in the case of Nuova Canottieri Olona, a private sporting club, can be strategically relevant for an increment of clients, because when other services need to address their users to a sporting club they will turn to the one they know better. Here social capital is intended as a strategic resource whose outcome is a private good in terms of higher profit. Whereas the goal of other public, private, non profit and religious services is not only to increase the profit through public funding, but also to offer a network of differentiated resources to problematic youth. They still have to compete against similar services for economic financing, but they also have to activate a collaborative network to address youth with multiple needs. In this case a general view of the local network of social and cultural services is essential to transform the awareness of the local offer into possible collaborations, that can be a valid source of social capital, where here social capital is intended as the product of collaborative relationships whose effect covers the entire community as the final beneficiaries are youths. In this perspective a brokerage role does not entail only personal and private advantages, as Burt says, but also collective benefits, as it produces social capital in terms of public good.

\section{Conclusions}

In this paper I analysed the brokerage role of social services that are able to activate different resources from cohesive subgroups. I combined two well known techniques, clique analysis and brokerage roles, on an original dataset in order to highlight who, within the network of social services in a local area of Milan, can count on strategic positions and can activate different resources from the ones embedded within cohesive subgroups. From a theoretical perspective, we saw how these resources can be used to develop collaborations, whose effects in terms of social capital are considered public as they spread on the whole community. On the other hand they can be used for private advantage in competitions for new customers and funding, where the social capital perspective is the one of Burt's, whose effects are interpreted as private and strategic goods.

From a methodological perspective, the strength of the method lies in the fact that brokerage roles are counted between groups which are formed according on relationships instead of attributes, thus the technique is based only on structural and relational properties instead of individual properties or attributes.

While the method seems to show some potential, something has to be said on the whole study: the way in which I collected data does not allow to explore the quality of the ties mapped. Knowing another service, as well as developing collaborations with it, does not mean that the relationship is positive and can lead to a stable tie: there could be the case in which two services know each other and already collaborate, but they might not be satisfied by the reciprocal work. My data do not permit to predict if the ties I found will produce further contacts, thus we will need longitudinal panels which reveal whose connections within the network are strong in terms of indicating reciprocal respect and continuous collaborations. This is not a secondary matter, as dealing with problematic youth needs long lasting interventions and commitment by the services' network. Also, I did not provide a grading scale of the kind of knowledge, thus the ties do not describe only one specific kind of relation, as they can be intended as superficial knowledge as well as reciprocal deep awareness.

Moreover, I do not know if brokers are aware of their position and use their strategic resources intentionally: what needs to be done is to qualitatively explore the self perception of services occupying different positions in the network, to give an account to the perceived positions and the advantage or constrains they implies.

Further research in these directions could reveal the strength of this method and show how being embedded in cohesive subgroups and acting as brokers could have different meaning for actors involved. 


\section{References}

Barbieri, P. (2005) 'Le fondamenta micro-relazionali del capitale sociale', Rassegna Italiana di Sociologia, XLVI (2) 345-384.

Borgatti,. S. P., Everett, M. G. and Freeman, L. C. (2002) UCINET 6 for Windows, Analytic Technologies, Cambridge, MA: Harvard University Press

Borgatti,. S. P., Everett, M. G. and Shirey, P. R. (1990) 'LS Sets, Lambda Sets and other cohesive subsets', Social Networks (12)337-357

Borgatti, S. P. (2002) NetDraw: Graph Visualization Software, Analytic Technologies, Cambridge, MA: Harvard University Press

Bourdieu, P. (1992) Réponses. Pour une anthropologie réflexive, Editions du Seuil, Paris

Burt, R. (1992) Structural Holes, Cambridge, MA: Harvard University Press

Coleman, J. S. (1998) Foundations of Social Theory, Belknap Press, Harvard

Folgheraitter, F. (2006) La cura delle reti, Erickson, Trento

Gould, J. And Fernandez, J. (1989) 'Structures of mediation: A formal approach to brokerage in transaction networks', Sociological Methodology (19) 89-126

Granovetter, M. (1973) 'The Strength of Weak Ties', American Journal of Sociology, 78 (6) 1360-1380

Krackhardt, D. (1998) 'Simmelian Tie: Super Strong and Sticky', in R. Kramer and M. Neale (eds.), Power and Influence in Organizations, Thousand Oaks: CA: SAGE

Krackhardt, D. (1999) Keynote address at UK Social Network Conference, (London 13-14 July 2007).

Krackhardt, D. and Kilduff, M. (2002) 'Structure, culture and Simmelian Ties in entrepreneurial firms', Social Networks (24) 279-290

Karckhardt, D. and Stern, R. N. (1988) 'Informal networks and organizational crises: an experimental simulation', Social Psychology Quarterly 51 (2) 123-140.

Lin, N. (2001) Social Capital: a theory of social structure and action, Cambridge: Cambridge University Press

Luce, R. and Perry, A. (1949) 'A method of matrix analysis of group structure', Psychometrika (14) 95-116

Putnam, R. D. (2000) Bowling Alone: the Collapse and Revival of American Community, New York: Simon \& Schuster

Seidman, S. and Foster, B. (1978) 'A graph theoretic generalization of the clique concept', Journal of Mathematical Sociology (6) 139-154

Simmel, G. (1983) Soziologie. Untersuchungen über die Formen der Vergesellschaftung, Berin: Duncker \& Humblot 
Table 5: brokerage roles between groups

\begin{tabular}{|c|c|c|c|c|c|c|c|}
\hline Group & Name & Coord. & Gatekeeper & Represent.. & Consultant & Liaison & Total \\
\hline 0 & Futsal & 2 & 4 & 2 & 0 & 2 & 10 \\
\hline 0 & 20 Hours & 2 & 3 & 2 & 0 & 5 & 12 \\
\hline 0 & G.S.S. Ambrogio & 70 & 86 & 39 & 0 & 42 & 237 \\
\hline 0 & Agorà & 60 & 55 & 52 & 0 & 33 & 200 \\
\hline 0 & Amici della musica & 16 & 22 & 24 & 0 & 22 & 84 \\
\hline 0 & Arcimetromondo & 15 & 21 & 11 & 0 & 8 & 55 \\
\hline 0 & Arcobaleno & 17 & 7 & 0 & 0 & 0 & 24 \\
\hline 0 & Arcobaleno & 39 & 11 & 35 & 0 & 3 & 88 \\
\hline 0 & Arno Stern & 3 & 7 & 1 & 0 & 1 & 12 \\
\hline 0 & $\begin{array}{l}\text { Ass. Sportiva } \\
\text { dilettantistica }\end{array}$ & 0 & 2 & 3 & 0 & 2 & 7 \\
\hline 0 & Atelier di pittura & 20 & 6 & 11 & 0 & 2 & 39 \\
\hline 0 & Atletico Milano & 18 & 4 & 4 & 0 & 2 & 28 \\
\hline 0 & Barona E. Satta & 6 & 0 & 5 & 0 & 0 & 11 \\
\hline 0 & $\begin{array}{l}\text { Biblioteca } \\
\text { Lorenteggio }\end{array}$ & 23 & 18 & 12 & 0 & 11 & 64 \\
\hline 0 & Scuola del Fumetto & 39 & 34 & 13 & 0 & 15 & 101 \\
\hline 0 & La Creta & 0 & 2 & 0 & 0 & 0 & 2 \\
\hline 0 & La Piazzetta & 3 & 6 & 3 & 0 & 1 & 13 \\
\hline 0 & C.F Boifava & 5 & 0 & 0 & 0 & 0 & 5 \\
\hline 0 & C.P.B.A. & 31 & 15 & 15 & 0 & 6 & 67 \\
\hline 0 & C.P.S. Soderini & 27 & 22 & 14 & 0 & 12 & 75 \\
\hline 0 & C.P.S. Vigilio & 27 & 24 & 23 & 0 & 18 & 92 \\
\hline 0 & C.T.F & 0 & 0 & 19 & 1 & 17 & 37 \\
\hline 0 & C.T.P. S. Paolino & 5 & 5 & 6 & 0 & 7 & 23 \\
\hline 0 & C.T.P. Zuara & 9 & 3 & 12 & 0 & 3 & 27 \\
\hline 0 & Mediazione familiare & 0 & 0 & 17 & 1 & 13 & 31 \\
\hline 0 & $\begin{array}{l}\text { CAM } \\
\text { Romane }\end{array}$ & 1 & 5 & 12 & 1 & 20 & 39 \\
\hline 0 & Clalb timbalaye & 0 & 0 & 0 & 0 & 0 & 0 \\
\hline
\end{tabular}




\begin{tabular}{|c|c|c|c|c|c|c|c|}
\hline Group & Name & Coord. & Gatekeeper & Represent.. & Consultant & Liaison & Total \\
\hline 0 & $\begin{array}{l}\text { Olimpo Sporting } \\
\text { Club }\end{array}$ & 22 & 8 & 8 & 0 & 4 & 42 \\
\hline 0 & Palauno & 66 & 8 & 37 & 0 & 3 & 114 \\
\hline 0 & Comunità Arianna & 24 & 36 & 8 & 0 & 17 & 85 \\
\hline 0 & Pietro Mongini & 0 & 0 & 0 & 0 & 0 & 0 \\
\hline 0 & $\begin{array}{l}\text { Centro Consulenza } \\
\text { Famiglia }\end{array}$ & 44 & 34 & 21 & 0 & 12 & 111 \\
\hline 0 & Centro incisione & 0 & 0 & 0 & 0 & 0 & 0 \\
\hline 0 & $\begin{array}{l}\text { Centro pittura } \\
\text { Consilvio }\end{array}$ & 3 & 1 & 7 & 0 & 1 & 12 \\
\hline 0 & $\begin{array}{ll}\text { Centro } & \text { Sportivo } \\
\text { Colombo } & \end{array}$ & 0 & 0 & 0 & 0 & 0 & 0 \\
\hline 0 & Centro studi attori & 12 & 8 & 6 & 0 & 1 & 27 \\
\hline 0 & $\begin{array}{l}\text { CFP Paullo, Bauer, } \\
\text { Vigorelli }\end{array}$ & 0 & 0 & 6 & 0 & 3 & 9 \\
\hline 0 & $\begin{array}{l}\text { S.Maria delle Grazie } \\
\text { al Naviglio }\end{array}$ & 29 & 6 & 31 & 0 & 1 & 67 \\
\hline 0 & Milano Sport & 11 & 17 & 5 & 0 & 9 & 42 \\
\hline 0 & La Conta & 12 & 3 & 8 & 0 & 1 & 24 \\
\hline 0 & Spazio aperto Gorki & 48 & 52 & 18 & 0 & 16 & 134 \\
\hline 0 & Handicap: su la testa! & 24 & 14 & 44 & 0 & 20 & 102 \\
\hline 0 & Stoppengò & 8 & 0 & 4 & 0 & 0 & 12 \\
\hline 0 & Cooperativa S.Rita & 8 & 7 & 18 & 0 & 12 & 45 \\
\hline 0 & $\begin{array}{l}\text { Cose dell'altro } \\
\text { mondo }\end{array}$ & 32 & 8 & 23 & 0 & 6 & 69 \\
\hline 0 & Teatro Primo Studio & 12 & 4 & 7 & 0 & 0 & 23 \\
\hline 0 & Cristiana Evangelica & 0 & 0 & 0 & 0 & 0 & 0 \\
\hline 0 & Don Orione & 159 & 77 & 65 & 0 & 25 & 326 \\
\hline 0 & Ellenica Ortodossa & 0 & 0 & 0 & 0 & 0 & 0 \\
\hline 0 & Enaip Lombardia & 25 & 25 & 14 & 1 & 10 & 75 \\
\hline 0 & L'impronta & 36 & 22 & 45 & 0 & 23 & 126 \\
\hline 0 & Ist professionale & 24 & 29 & 21 & 1 & 17 & 92 \\
\hline
\end{tabular}




\begin{tabular}{|c|c|c|c|c|c|c|c|}
\hline Group & $\begin{array}{l}\text { Name } \\
\text { B.Oriani }\end{array}$ & Coord. & Gatekeeper & Represent.. & Consultant & Liaison & Total \\
\hline 0 & Sarabanda & 18 & 25 & 29 & 0 & 25 & 97 \\
\hline 0 & $\begin{array}{l}\text { Istituto d'arte Beato } \\
\text { Angelico }\end{array}$ & 3 & 0 & 0 & 0 & 0 & 3 \\
\hline 0 & Sport ecologici & 0 & 0 & 0 & 0 & 0 & 0 \\
\hline 0 & $\begin{array}{l}\text { Immacolata } \\
\text { Concezione }\end{array}$ & 11 & 11 & 0 & 0 & 0 & 22 \\
\hline 0 & Piscina Cardellino & 47 & 33 & 55 & 0 & 34 & 169 \\
\hline 0 & $\begin{array}{l}\text { Sviluppo } \\
\text { Promozione }\end{array}$ & 23 & 32 & 19 & 0 & 15 & 89 \\
\hline 0 & Istituto Cavalieri & 35 & 12 & 81 & 0 & 20 & 148 \\
\hline 0 & Testimoni di Geova & 0 & 7 & 0 & 0 & 4 & 11 \\
\hline 0 & Istituto Resistenza & 3 & 22 & 7 & 0 & 27 & 59 \\
\hline 0 & S.Giovanni Bono & 30 & 10 & 62 & 0 & 13 & 115 \\
\hline 0 & WWF & 14 & 2 & 0 & 0 & 0 & 16 \\
\hline 0 & Mani Tese & 28 & 13 & 32 & 0 & 8 & 81 \\
\hline 0 & Le Tre Fontane & 8 & 11 & 4 & 0 & 10 & 33 \\
\hline 0 & Principessa & 4 & 3 & 0 & 0 & 0 & 7 \\
\hline 0 & S.Bernadetta & 39 & 19 & 73 & 0 & 15 & 146 \\
\hline 0 & $\begin{array}{l}\text { MB Sportello Marco } \\
\text { Biagi }\end{array}$ & 6 & 4 & 6 & 0 & 3 & 19 \\
\hline 0 & $\begin{array}{l}\text { Liceo scientifico A. } \\
\text { Carrel }\end{array}$ & 11 & 3 & 17 & 0 & 1 & 32 \\
\hline 0 & Ufficio volontariato & 24 & 21 & 17 & 0 & 9 & 71 \\
\hline 0 & UTM & 30 & 4 & 19 & 0 & 2 & 55 \\
\hline 1 & G.S. La Spezia & 0 & 18 & 10 & 28 & 15 & 71 \\
\hline 1 & Iris 1914 & 0 & 17 & 3 & 7 & 9 & 36 \\
\hline 1 & A.S. Barona & 0 & 30 & 2 & 9 & 11 & 52 \\
\hline 1 & Canottieri Olona & 0 & 69 & 35 & 120 & 128 & 352 \\
\hline 2 & Piscina Solari & 0 & 4 & 3 & 44 & 83 & 134 \\
\hline 2 & Canottieri Milano & 0 & 12 & 1 & 28 & 55 & 96 \\
\hline
\end{tabular}




\begin{tabular}{|c|c|c|c|c|c|c|c|}
\hline Group & Name & Coord. & Gatekeeper & Represent.. & Consultant & Liaison & Total \\
\hline 3 & La cordata & 0 & 24 & 41 & 139 & 202 & 406 \\
\hline 3 & Cascina Bianca & 0 & 11 & 32 & 72 & 110 & 225 \\
\hline 3 & Colore & 0 & 11 & 31 & 70 & 95 & 207 \\
\hline 4 & CD Giambellino & 0 & 21 & 84 & 229 & 243 & 577 \\
\hline 4 & CAM La Spezia & 0 & 18 & 1 & 6 & 15 & 40 \\
\hline 4 & Creta & 1 & 15 & 9 & 23 & 27 & 75 \\
\hline 4 & Comunità Nuova & 3 & 125 & 67 & 380 & 460 & 1035 \\
\hline 4 & Paspartù & 3 & 16 & 103 & 114 & 183 & 419 \\
\hline 5 & $\begin{array}{ll}\text { Liceo } & \text { Scientifico } \\
\text { Vittorini } & \end{array}$ & 1 & 60 & 27 & 141 & 41 & 270 \\
\hline 5 & A77 & 0 & 70 & 41 & 148 & 138 & 397 \\
\hline 5 & $\begin{array}{l}\text { Istituto tecnico } \\
\text { Giorgi }\end{array}$ & 1 & 53 & 56 & 201 & 137 & 448 \\
\hline 5 & $\begin{array}{l}\text { Liceo } \\
\text { Marconi }\end{array}$ & 1 & 60 & 49 & 172 & 167 & 449 \\
\hline 5 & Città Dei Mestieri & 0 & 5 & 27 & 13 & 24 & 69 \\
\hline 6 & Ser.T. Forze Armate & 0 & 17 & 10 & 128 & 147 & 302 \\
\hline 6 & Cedag Irda & 0 & 6 & 23 & 82 & 216 & 327 \\
\hline 7 & CAM S. Paolino & 0 & 6 & 19 & 90 & 152 & 267 \\
\hline 7 & $\begin{array}{l}\text { Biblioteca } \\
\text { S.Ambrogio }\end{array}$ & 0 & 11 & 9 & 100 & 96 & 216 \\
\hline 8 & Il Balzo & 0 & 41 & 53 & 262 & 416 & 772 \\
\hline 8 & CDD Narcisi & 0 & 9 & 1 & 33 & 79 & 122 \\
\hline 8 & CDD De Nicola & 0 & 18 & 2 & 51 & 114 & 185 \\
\hline 9 & Comuna Baires & 0 & 26 & 43 & 177 & 229 & 475 \\
\hline 9 & Teatri Possibili & 0 & 10 & 3 & 9 & 27 & 49 \\
\hline 9 & Mami Wata & 0 & 0 & 40 & 21 & 19 & 80 \\
\hline
\end{tabular}

